\title{
GERENCIAMENTO DOS RESÍDUOS DE SERVIÇOS DE SAÚDE EM CONSULTÓRIOS ODONTOLÓGICOS DE TRÊS PASSOS/RS
}

\author{
Micaeli Berwaldt Saul Longhi', Ramiro Pereira Bisognin², Eduardo Lorensi \\ de Souza ${ }^{3}$, Danni Maisa da Silva ${ }^{4}$ e Robson Evaldo G. Bohrer ${ }^{5}$
}

\begin{abstract}
Resumo: Os geradores de resíduos de serviços de saúde (RSS) devem possuir o Plano de Gerenciamento de RSS (PGRSS) que tem como intuito planejar as formas de gerenciamento, acondicionamento e disposição dos resíduos gerados nos estabelecimentos de saúde. Diante de tal relevância, o presente trabalho teve como objetivo avaliar o gerenciamento dos resíduos de saúde em diferentes consultórios odontológicos do município de Três Passos/RS. A metodologia adotada foi de cunho quali-quantitativa, aplicando-se um questionário a 28 dos 46 consultórios odontológicos particulares, com o intuito de caracterizar os tipos de resíduos de saúde gerados, quantificar seu volume e identificar as formas de disposição final. Verificou-se que os principais resíduos gerados nos consultórios são pertencentes ao Grupo A, resíduos biológicos. Somente 10 consultórios forneceram informações sobre número de pacientes e volume de resíduos gerados. Foi identificado também que os profissionais possuem pouco entendimento sobre as formas de disposição final que a empresa responsável pela coleta dá aos RSS. Dos consultórios estudados, sete não possuíam PGRSS. Desta forma, fica evidente a atenção que é necessária se dar ao gerenciamento de resíduos de serviços de saúde, para que as legislações vigentes sejam atendidas.
\end{abstract}

Palavras-chave: Consultórios odontológicos. Resíduos de serviços de saúde. Gerenciamento.

\section{Introdução}

O descarte de resíduos de serviços de saúde (RSS) junto com outros resíduos domésticos em aterros sanitários é uma prática comum, porém, irregular $\mathrm{e}$ inadequada. O gerenciamento adequado dos RSS envolve ações de manuseio, armazenamento, coleta e destino final específico (PEDROSA et al., 2007; GARBIN et al., 2015), pois são resíduos que podem acarretar efeitos adversos tanto à saúde da população quanto à qualidade do meio ambiente. Sendo assim, estes resíduos necessitam de disposição final específica (AGÊNCIA NACIONAL DE VIGILÂNCIA SANITÁRIA (ANVISA), 2004). São produzidos diariamente toneladas de resíduos residenciais e comerciais, sendo que cerca de $2 \%$ são RSS que necessitam de atenção especial de gerenciamento, desde a geração até a disposição final (OLIVEIRA; MOREIRA, 2012).
Conforme diretriz estabelecida pela Organização Mundial de Saúde (WHO, 1983), "O gerenciamento dos resíduos de saúde envolve a remoção e disposição dos resíduos da maneira mais higiênica possível, através de métodos que, em todas as etapas, minimizem o risco à saúde e ao meio ambiente."

Entende-se por RSS aqueles gerados por estabelecimentos prestadores de assistência à saúde humana e veterinária, laboratoriais, necrotérios e funerárias, instituições de ensino e pesquisa na área da saúde, entre outros (ANVISA, 2006). No momento da geração, os RSS devem ser separados de acordo com a sua classificação para evitar maiores contaminações e também minimizar os problemas ocorridos (GARBIN et al., 2015).

De acordo com a resolução da diretoria colegiada (RDC) №. 306 (ANVISA, 2004), os RSS são classificados como: Grupo A composto por resíduos biológicos que podem causar risco de infecções; Grupo B

\footnotetext{
1'E-mail: micaeli_saul@hotmail.com

${ }^{2}$ E-mail: ramirobisognin@yahoo.com.br do Sul (UERGS).

${ }^{3}$ E-mail: elorensi@yahoo.com.br

${ }^{4}$ E-mail: danni.maisa@yahoo.com.br

${ }^{5 * E-m a i l: ~ g e h l e n . b o h r e r @ g m a i l . c o m ~}$
}

Rua Cipriano Barata, 211. Bairro Érico Veríssimo. Três Passos/RS. CEP: 986000-000. Universidade Estadual do Rio Grande 


\section{REA - Revista de estudos ambientais (Online) v.20, n. 2, p.49-61, jul./dez. 2018}

composto por resíduos contendo substancias químicas que podem apresentar risco à saúde e ao meio ambiente; Grupo C composto por materiais radioativos; Grupo D composto por resíduos comuns e recicláveis; e Grupo E composto por materiais perfurocortantes. Os RSS segundo a NBR 10004 da Associação Brasileira de Normas Técnicas (ABNT, 2004) são classificados como Classe I - perigosos, pois podem apresentar características como: inflamabilidade, corrosividade, reatividade, toxicidade ou patogenicidade.

Todo gerador de RSS deve elaborar um Plano de Gerenciamento de Resíduos de Serviços de Saúde (PGRSS), que é um documento que aponta e descreve as ações relacionadas com o manejo dos resíduos sólidos nos estabelecimentos da saúde. Neste plano devem constar as seguintes etapas de manejo: segregação, acondicionamento, identificação, transporte interno, armazenamento temporário, tratamento, armazenamento externo, coleta e transporte externos, e disposição final. O PGRSS deve estar baseado nas características e volume compatíveis com as normas locais estabelecidas pelos órgãos competentes e deve ficar disponível para consulta mediante solicitação do órgão fiscalizador e público em geral (ANVISA, 2004; OLIVEIRA; MOREIRA, 2012).

Para cada tipo de resíduo gerado há uma forma de segregação e acondicionamento, que leva em consideração a identificação do grupo ao qual esses resíduos pertencem, como: Grupo A - sacos brancos com simbologia infectante, Grupo B galões coletores, Grupo C - recipientes blindados, Grupo D - lixeiras com sacos pretos e Grupo E - recipientes rígidos (ANVISA, 2004). Segundo a NBR no 9191 (ABNT, 2000), as embalagens para armazenamento dos resíduos sólidos devem ser de material resistente a ruptura e vazamento, impermeável, e deve-se respeitar os limites de peso de cada recipiente, sendo proibido o esvaziamento e reaproveitamento dos mesmos.

Os serviços odontológicos necessitam de uma maior ampliação de estudos, pois também são responsáveis pela produção de resíduos de serviços de saúde com potencial contaminante se forem manuseados da forma errada (ANVISA, 2006; GARBIN et al., 2015). A prática odontológica está vinculada com a geração de vários RSS, desde resíduos biológicos como luvas, gaze, algodão ou qualquer material contaminado por fluído corporal, como também resíduos químicos, tais como anestésicos, saneantes, desinfetantes, entre outros, e perfurocortantes como agulhas, brocas, bisturis, entre outros, que devem ser descartados de forma adequada. Também são gerados resíduos comuns como materiais recicláveis que podem ser destinados aos aterros sanitários ou voltar a cadeia produtiva (ANVISA, 2006; OLIVEIRA; MOREIRA, 2012).

A falta de conhecimento dos cirurgiões-dentistas em relação aos resíduos gerados nos consultórios pode causar vários danos, o que leva a necessidade de maior compreensão dos profissionais em relação ao meio ambiente e a sustentabilidade, em virtude dos vários problemas associados à má administração dos resíduos odontológicos, com potencial nocivo à vida humana (OLIVEIRA; MOREIRA 2012; GARBIN et al., 2015). Os profissionais precisam de maior sensibilização em relação aos problemas que - mau gerenciamento dos resíduos odontológicos pode causar ao meio ambiente (CARDOSO, PASSOS; CARNEIRO, 2015).

Nesse sentindo, no presente trabalho objetivou-se avaliar o gerenciamento dos RSS em diferentes consultórios odontológicos particulares do município de Três Passos/RS, levando em consideração a preocupação com o meio ambiente e a saúde humana.

\section{Metodologia}

\section{1 Área de estudo}

O presente trabalho foi realizado no município de Três Passos/RS, que possui 46 consultórios odontológicos particulares localizados no perímetro urbano, principalmente na área central do município. Três Passos possui uma população de 24.640 mil habitantes, dos quais $79,51 \%$ residem no perímetro urbano. A área total do município é de 268,396 km² (Figura 1), sendo a economia baseada principalmente na produção agrícola, produção de suínos e gado leiteiro (IBGE, 2015).

\subsection{Levantamento de dados}

Foi realizado um levantamento qualiquantitativo em consultórios odontológicos particulares, a partir da aplicação de um questionário estruturado contendo perguntas descritivas e objetivas baseadas nas normas do Conselho Nacional do Meio Ambiente 


\section{REA - Revista de estudos ambientais (Online) v.20, n. 2, p.49-61, jul./dez. 2018}

(CONAMA) e Agência Nacional de Vigilância Sanitária (ANVISA). Os questionários foram aplicados por um único pesquisador, e as perguntas foram baseadas nos tipos de resíduos de serviços de saúde gerados, volume, forma de gerenciamento, acondicionamento, disposição final e, ainda, se os consultórios odontológicos possuíam PGRSS, conforme estudos similares realizados (GARBIN et al., 2015; OLIVEIRA; MOREIRA, 2012; SILVA; HOPPE, 2005; NAZAR; PORDEUS; WERNECK, 2005; PEDROSA et al., 2007; CARDOSO, PASSOS; CARNEIRO, 2015).

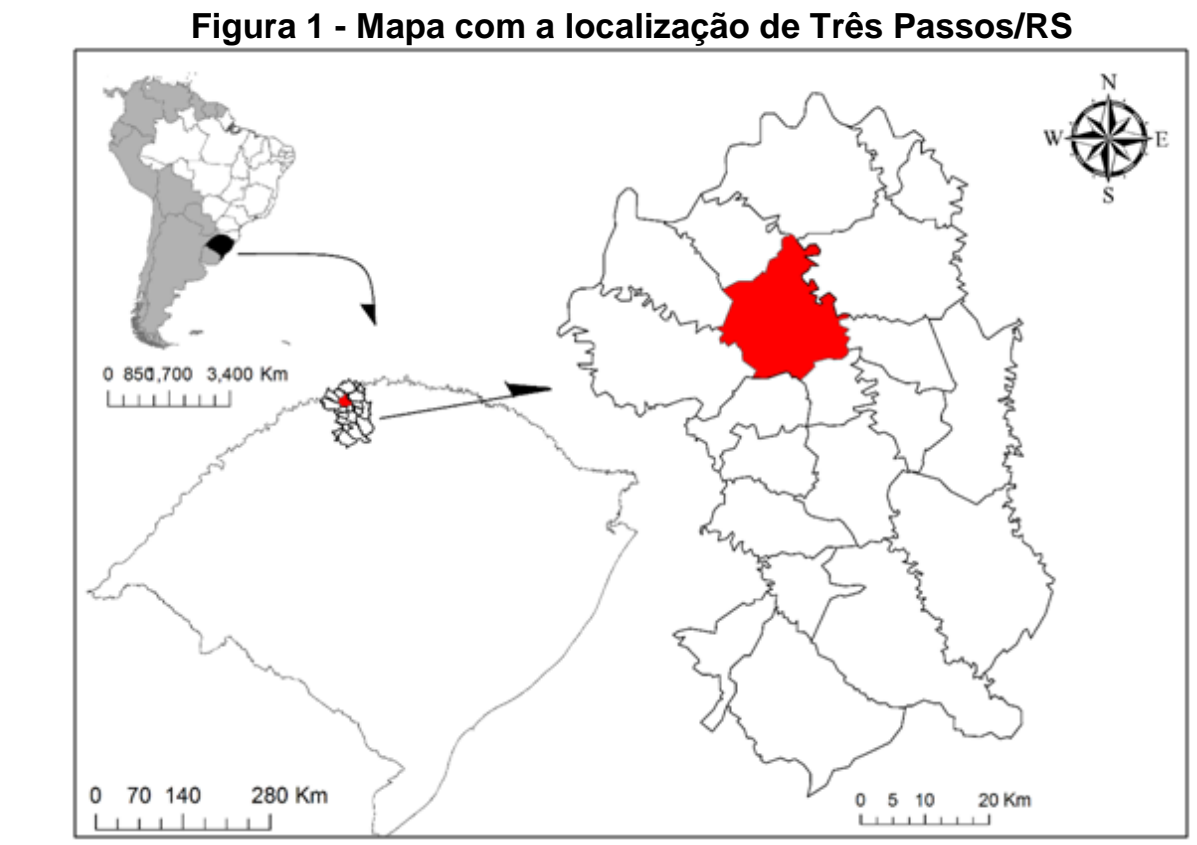

Fonte: Vasconcelos (2017)

\subsubsection{Caracterização dos resíduos de serviços de saúde gerados}

A caracterização dos consultórios odontológicos e dos resíduos gerados ocorreu pela aplicação do mesmo questionário mencionado, porém, com perguntas descritivas e objetivas, realizado em 28 consultórios odontológicos particulares. Para essa caracterização foi considerado o número de cirurgiões em cada consultório, as especialidades atendidas, o número de pacientes atendidos no consultório no período de um mês e as perguntas foram pertinentes aos tipos de RSS gerados (PEDROSA et al., 2007).

\subsubsection{Quantificação do volume e armazenamento dos resíduos}

Foram elaboradas perguntas sobre o
volume gerado, o tipo r de
armazenamento/embalagem usado nos
consultórios e qual é o tipo de
acondicionamento utilizado até o momento da
coleta dos resíduos nos consultórios

odontológicos. Com o número de pacientes atendidos e o volume mensal de resíduos gerados foi realizada a média para quantificar o volume oriundo de cada atendimento.

\subsubsection{Identificação do destino final dos resíduos}

A identificação do destino final dos resíduos ocorreu por meio de perguntas sobre qual empresa é responsável pela coleta desses resíduos e qual o destino final dado aos resíduos. Também foram levantadas informações sobre a frequência de coleta realizada pela empresa no consultório. A pesquisa visou obter informações relacionadas com 0 gerenciamento dos resíduos odontológicos, levando em consideração principalmente se a disposição final desses resíduos está de acordo com a legislação especifica sobre RSS, a resolução no 358 (CONAMA, 2005), como enfatizado por Pedrosa et al. (2007). Também foi levado em consideração se os consultórios possuíam PGRSS (ANVISA, 2004). 


\section{REA - Revista de estudos ambientais (Online) v.20, n. 2, p.49-61, jul./dez. 2018}

\subsection{Avaliação de estratégias para análise da disposição final dos resíduos}

A avaliação da disposição final se deu através de pesquisas bibliográficas, levando em consideração a resolução no 358 (CONAMA, 2005) e a RDC o 306 (ANVISA, 2004). Foram realizadas pesquisas nos sites das empresas que prestam os serviços de coleta e destinação final dos RSS aos consultórios estudados, a fim de identificar a conformidade das técnicas empregadas com as normativas supracitadas, bem como 0 valor cobrado.

\section{Resultados}

O estudo foi realizado em 28 consultórios odontológicos particulares no município de Três Passos/RS, o que representa uma amostra de $60,87 \%$ dos consultórios odontológicos particulares do município. Esses consultórios atendem diferentes especialidades odontológicas (Figura 2), sendo que em alguns consultórios são atendidas mais de uma especialidade. Os questionários respondidos foram numerados aleatoriamente de Q1 a Q28 para facilitar a compilação dos dados.

\section{Figura 2 - Especialidades atendidas nos consultórios odontológicos de Três Passos/RS}

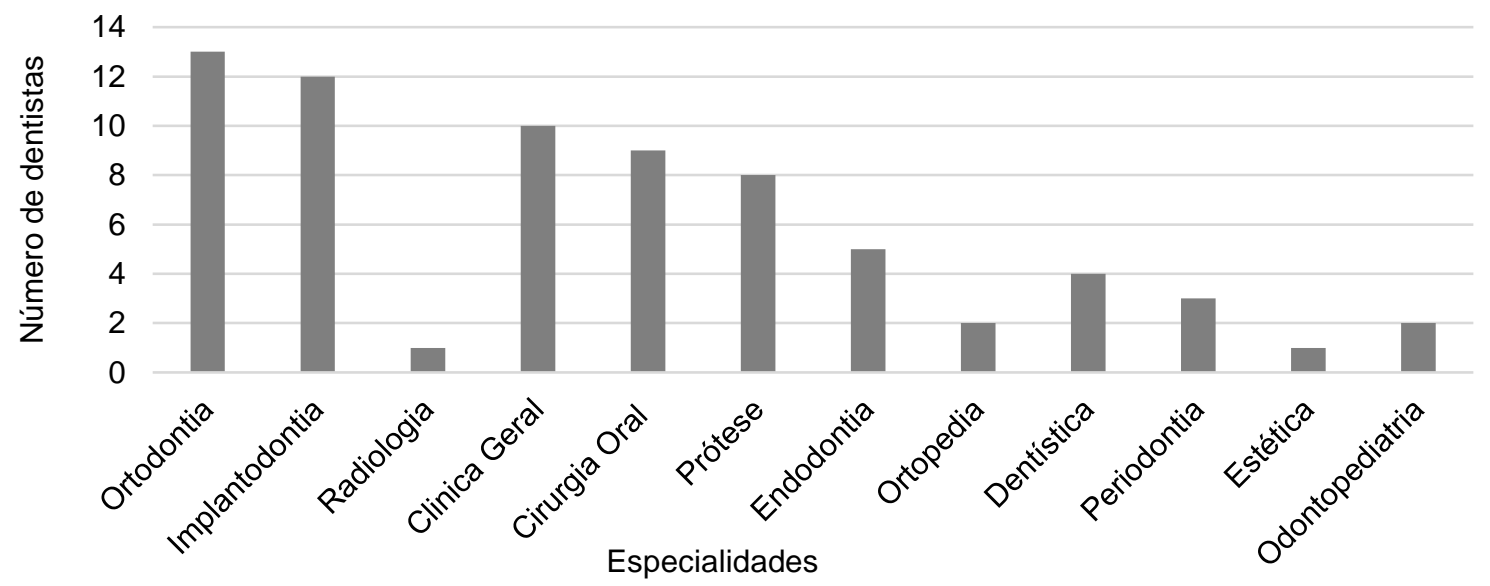

Fonte: Autores (2018)

A especialidade mais atendida nos consultórios estudados, sendo equivalente a 13 profissionais, é a ortodontia que é a especialidade voltada para a prática de correção do posicionamento dos dentes e dos ossos maxilares através de aparelho ortodôntico. Essa especialidade é a mais praticada pelos profissionais da área pelo elevado número de pacientes interessados no serviço, bem como pela maior geração de renda. A implantodontia ocupa o segundo lugar, com 12 especialistas, essa é a prática de colocar suporte ou estruturas de metal no osso maxilar para substituir as raízes dentarias, é um dos métodos mais caros para substituição dos dentes, mas também um dos mais procurados, pois é o que mais se assemelha com o dente natural. As outras especialidades são clínica geral, cirurgia oral e prótese, que também possuem número expressivo de profissionais, tendo também profissionais nas áreas de endodontia, dentística, periodontia, ortopedia e odontopediatria.

A radiologia foi a especialidade identificada somente por um consultório estudado, que consiste no diagnóstico por imagem, juntamente com laudos e documentações do complexo buco-maxilofacial e estruturas anexas. A estética, que consiste na transformação do sorriso através de clareamento, restaurações estéticas de resinas na cor do dente, facetas de porcelana, lentes de contato dentais, como também aplicação de botox e preenchimentos faciais foi identificada somente por um consultório. No entanto, este é um tipo de serviço que está em expansão.

Considerando-se que, segundo Silva, Shiga e Colares-Santos (2015), o Brasil é o país com o maior número de cirurgiões dentistas do mundo, e que, de acordo com Anceles et al. (2016), os serviços odontológicos geram resíduos com potencial de causar riscos à saúde pública, ocupacional 


\section{REA - Revista de estudos ambientais (Online) v.20, n. 2, p.49-61, jul./dez. 2018}

e ambiental, torna-se fundamental o gerenciamento adequado destes resíduos, de modo a reduzir ao mínimo os fatores de riscos a estes associados.

\subsection{Caracterização e quantificação dos resíduos gerados}

Para caracterizar a geração per capita por consultórios foi levado em consideração o número de cirurgiões dentistas que atendiam em cada consultório, sendo que esse número variou de um até quatro especialistas por consultório, como mostra a Figura 3.

Como nem todos os consultórios quiseram responder as questões sobre número de pacientes atendidos e volume de resíduos gerados em um mês foi efetuada a média a partir dos dados obtidos de 10 consultórios que forneceram as informações. Assim chegou-se a média mensal de 155 pacientes por consultório e volume de 81 litros de RSS, o que resulta na geração de 0,52 litros de RSS por paciente atendido, conforme dados apresentados na Tabela 1.

Figura 3 - Número de cirurgiões dentistas por consultório odontológico de Três Passos/RS

5

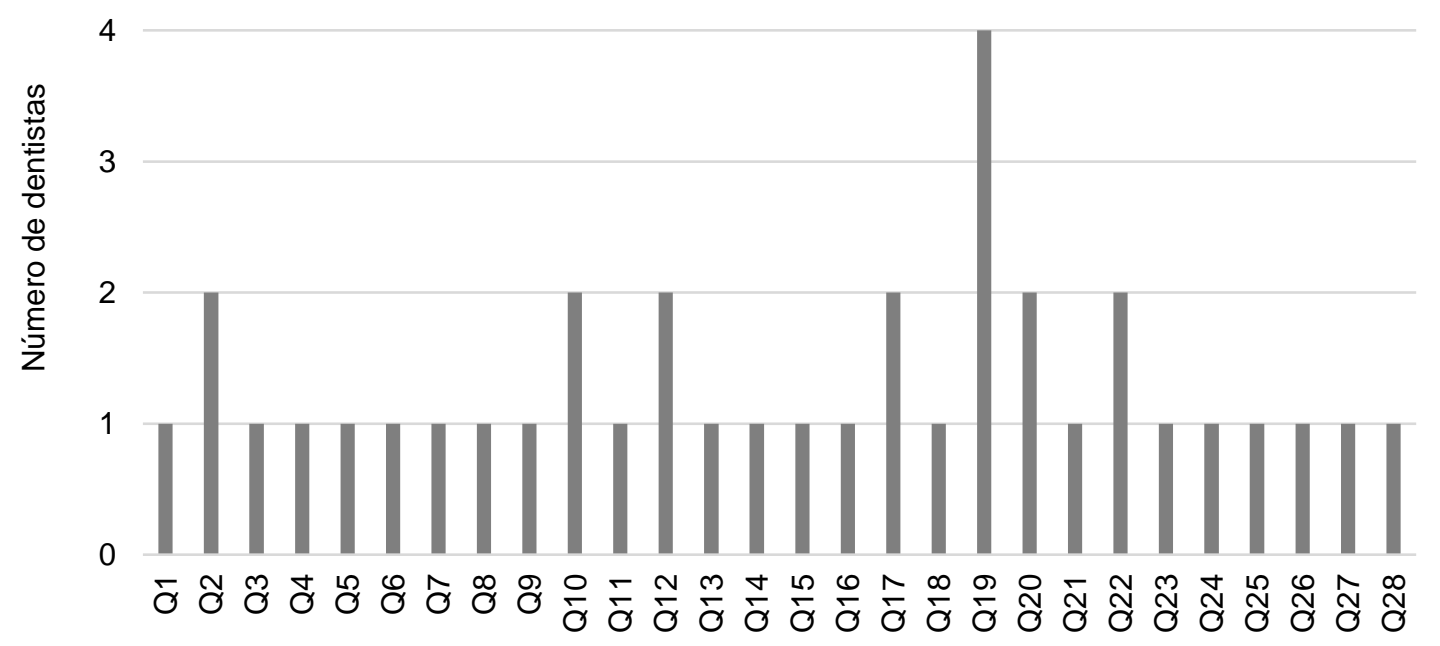

Identificação dos formulários aplicados nos consultórios

Nota: Q1 a Q28 referem-se aos questionários aplicados nos 28 consultórios odontológicos. Fonte: Autores (2018)

Tabela 1 - Número de pacientes e volumes de resíduos gerados nos consultórios odontológicos de Três Passos/RS

\begin{tabular}{cccc}
\hline $\begin{array}{c}\text { Identificação do } \\
\text { consultório }\end{array}$ & $\begin{array}{c}\text { Número de pacientes } \\
\text { atendidos (Mês) }\end{array}$ & $\begin{array}{c}\text { Volume gerado } \\
\text { (Litros/mês) }\end{array}$ & $\begin{array}{c}\text { Média dos resíduos } \\
\text { por paciente } \\
\text { (Litros/mês) }\end{array}$ \\
\hline Q5 & 100 & 40 & 0,4 \\
Q9 & 210 & 200 & 0,95 \\
Q10 & 60 & 30 & 0,5 \\
Q12 & 350 & 120 & 0,34 \\
Q13 & 250 & 120 & 0,48 \\
Q19 & 180 & 80 & 0,44 \\
Q20 & 120 & 120 & 1 \\
Q21 & 40 & 20 & 0,5 \\
Q22 & 200 & 20 & 0,1 \\
Q26 & 45 & 60 & 1,33 \\
\hline Média & 155 & 81 & 0,52 \\
\hline
\end{tabular}

Fonte: Autores (2018) 
Silva e Hoppe (2005) descrevem a geração total de $0,241 \mathrm{~kg} /$ dentista/dia, em um estudo realizado em consultórios odontológicos, sendo que os principais resíduos gerados são do grupo $\mathrm{A}$, perfazendo um total de $0,180 \mathrm{~kg} /$ dentista/dia. Embora a Odontologia, como um serviço da área da saúde também gere RSS, segundo Leal (2015), não geram em seus ambientes quantidades consideráveis destes resíduos, como as instituições hospitalares, por exemplo.

Os resíduos gerados nos consultórios estudados são pertencentes ao Grupo A, B, $C$, $D$ e $E$, sendo que principalmente são gerados os resíduos pertencentes ao Grupo
A, resíduos biológicos como luvas, algodão, gaze, sugadores de saliva, entre outros. A Figura 4 apresenta a identificação de todos os resíduos verificados na pesquisa nos diferentes consultórios investigados. Porém, alguns consultórios não geram todos os resíduos mencionados, assim, quando se verificou a geração de um resíduo em determinado consultório este foi registrado como "sim" e quando o resíduo não foi gerado no consultório em questão se registrou como "não". Como a pesquisa foi destinada aos RSS gerados por consultórios não foram contabilizados os resíduos do grupo D, composto por resíduos comuns e recicláveis.

Figura 4 - Principais resíduos de serviços de saúde gerados nos consultórios odontológicos de Três Passos/RS

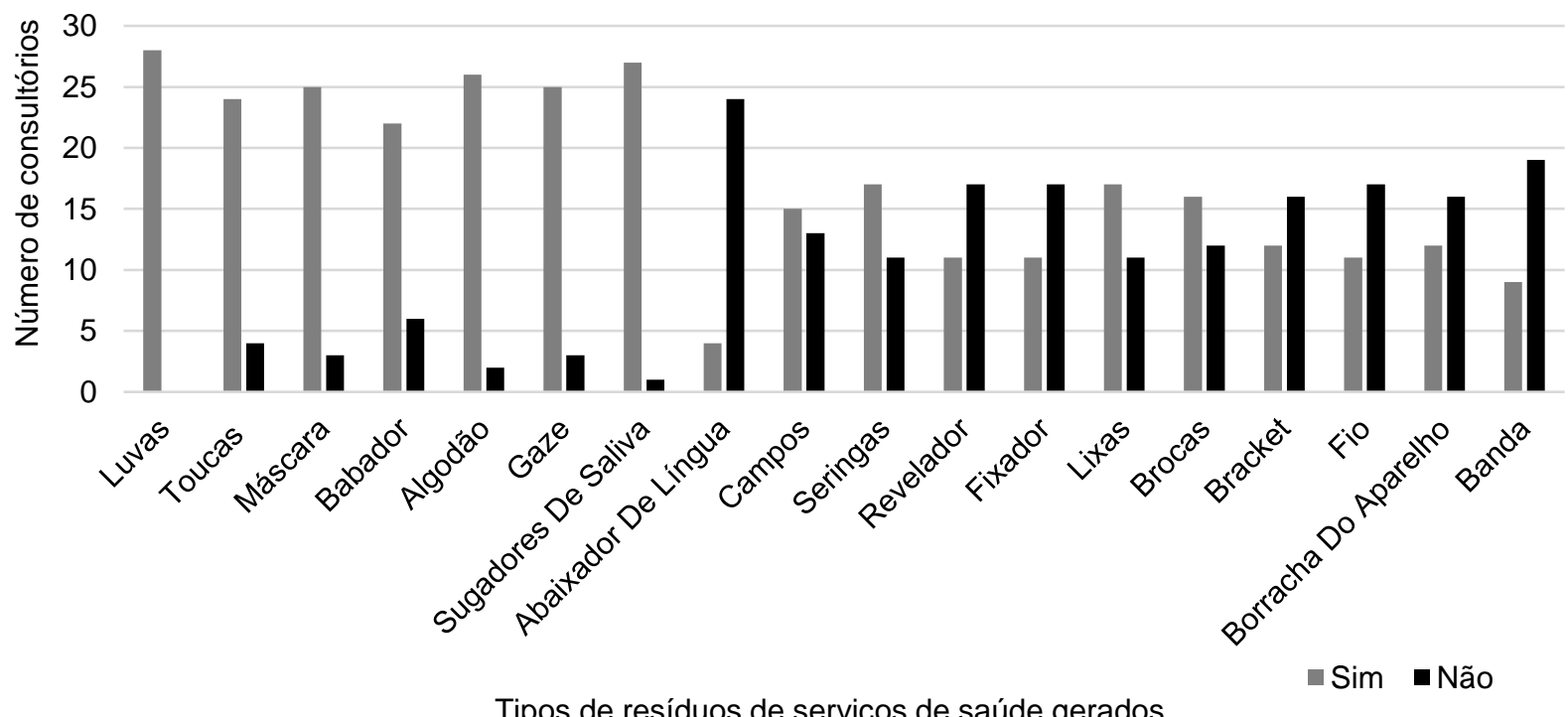

Fonte: Autores (2018)

O questionário ainda possuía a opção de marcar outros. Nesse campo, alguns consultórios citaram fio dental, gesso, lâmina de bisturi, amálgama, mercúrio, resinas e material de moldagem. Estes também devem ser descartados de acordo com seu grupo de RSS.

Entre os resíduos citados como outros, o amálgama merece destaque, pois é utilizado para fazer restauração nos dentes. Ele é composto por prata, mercúrio, estanho e cobre, podendo também conter traços de zinco, platina e/ou paládio dependendo do fabricante. Logo, se não descartado de forma correta pode causar danos à saúde humana $\mathrm{e}$ ao meio ambiente. Não há nenhum estudo que comprove a causa de danos na saúde por esse resíduo se o mesmo for manejado de forma correta, mas em alguns países o uso desse material já foi proibido (SANTOS et al., 2016). Em estudo realizado por Anceles et al. (2016), no município de São Luís, no Estado do Maranhão, de 74 consultórios odontológicos entrevistados, 13,5\% informaram que enviavam os restos de amálgama junto com o resíduo que seria incinerado, 9,4\% que descartaram amálgama no lixo comum e $29,7 \%$ informaram que o colocavam em recipiente inquebrável e o enviavam para reciclagem, enquanto que 


\section{REA - Revista de estudos ambientais (Online) v.20, n. 2, p.49-61, jul./dez. 2018}

$43,2 \%$ dos dentistas informaram que não usavam amálgama. Nos últimos anos esse material vem sendo substituído pelas resinas compostas que são da cor do dente, fazendo com que a aparência fique mais natural. Dessa forma, o cirurgião dentista tem grande responsabilidade no descarte adequado de resíduos do consultório no intuito de não contaminar o meio ambiente e a si mesmo, mantendo o uso racional da amálgama de prata, que ainda é considerada benéfica na Odontologia (CLARO et al., 2003; GRIGOLETTO et al., 2008).

O principal resíduo gerado em todos os consultórios é a luva que é item obrigatório no atendimento dos pacientes e deve ser trocada a cada atendimento, também é item obrigatório a máscara, mas três consultórios responderam que não descartam esse tipo de resíduo. O uso de toucas é opcional, mas 24 consultórios estudados fazem 0 descarte desse resíduo, ou seja, utilizam nos atendimentos. Também estão entre os principais resíduos descartados sugadores de saliva, algodão, gaze e babador.

Os abaixadores de língua representam os RSS de menor geração nos consultórios estudados, apenas quatro informaram o descarte desse material. Tal fato se deve a substituição dos abaixadores de língua descartáveis, ou seja, de madeira, por outros de material cirúrgico que podem ser esterilizados e reutilizados. Os resíduos como fio, bracket, borracha de aparelho e banda, são gerados pelos consultórios com especialidade em ortodontia. Já os campos cirúrgicos estéreis são gerados por consultórios com especialidade em implantodontia. Os resíduos líquidos, como revelador e fixador, são descartados pelos consultórios que realizam radiografias (raio$x)$. Esses resultados corroboram os observados por Ferreira, Gorges e Silva (2009), que constataram que nas atividades odontológicas muitos resíduos são gerados (agulhas, seringas, gazes, bandagens, algodões, meios de culturas, sangue coagulado, luvas descartáveis, remédios com prazos de validade vencidos, instrumentos de resina sintética e filmes fotográficos de raio $\mathrm{x}$ ).

\subsubsection{Armazenamento e acondicionamento dos resíduos gerados pelos consultórios}

No questionário também haviam questões relacionadas aos tipos de embalagens de armazenamento utilizadas nos consultórios odontológicos para a disposição dos RSS gerados. As principais respostas obtidas estão descritas na Figura 5, sendo que houve mais de uma resposta em alguns consultórios para essa questão. Em cinco questionários foram respondidos que as embalagens utilizadas para armazenamento dos RSS eram fornecidas pela empresa que realiza a coleta dos resíduos no consultório.

\section{Figura 5 - Embalagens de armazenamento de resíduos utilizadas nos consultórios odontológicos de Três Passos/RS}

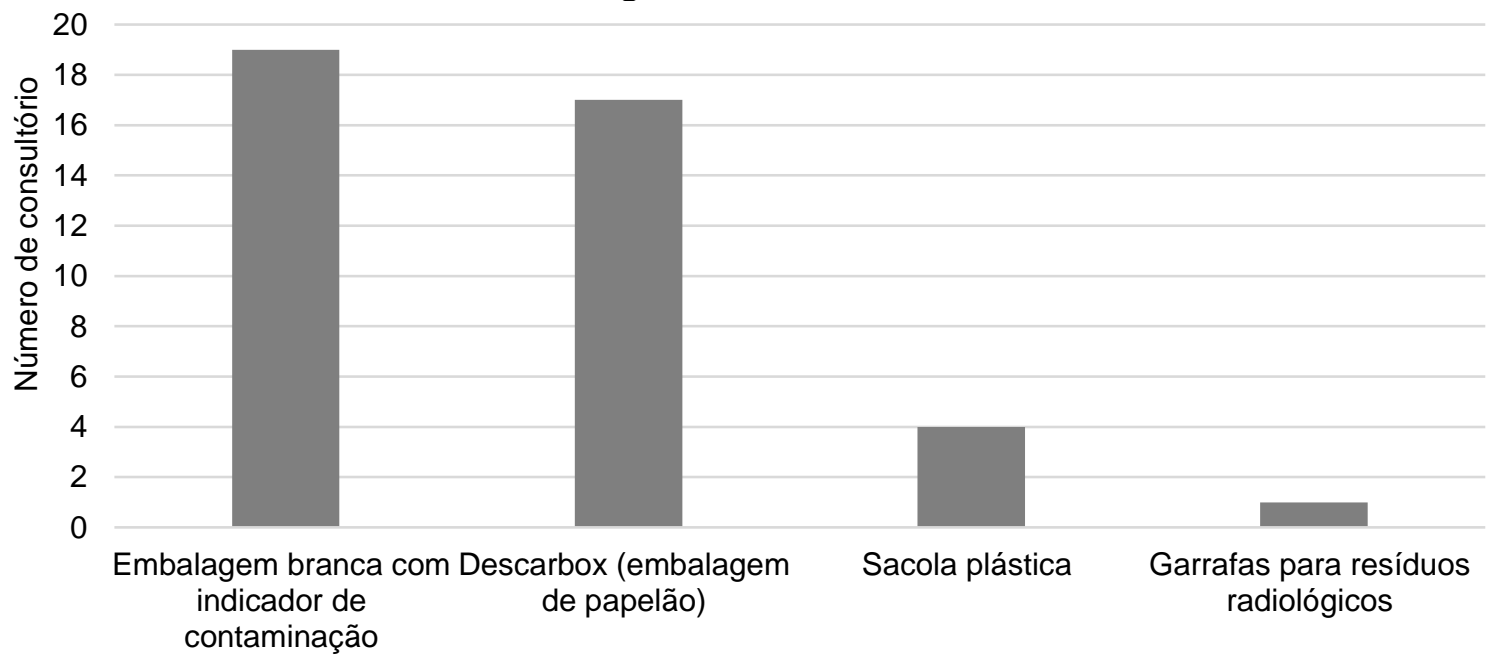

Embalagem de armazenamento utilizadas

Fonte: Autores (2018) 


\section{REA - Revista de estudos ambientais (Online) v.20, n. 2, p.49-61, jul./dez. 2018}

Segundo a NBR 9191 (ABNT, 2000), a forma de acondicionamento dos RSS deve ser em sacos brancos leitosos, resistentes, impermeáveis e identificados com a simbologia do resíduo infectante, sendo que o mesmo deve ser preenchido somente dois terços do volume para assim facilitar o fechamento. $\mathrm{Na}$ pesquisa realizada por Pedrosa et al. (2007), $81,1 \%$ dos entrevistados acondicionava o material em outros tipos de sacos plásticos de cores diversas, sem especificação sobre o caráter infectante, e também sem ser separado dos resíduos comuns. Já em trabalho publicado por Silva, Shiga e Colares-Santos (2015) constatou-se que, em todas as clínicas odontológicas pesquisadas todos os resíduos comuns ou infectantes são descartados em sacos de lixo apropriados, sendo que, os resíduos comuns são colocados em saco preto e os infectantes em saco branco leitoso com a gramatura estipulada pela ANVISA, com vistas a facilitar a identificação pelos profissionais que manuseiam os resíduos.

Tendo em vista a normativa RDC no 306 (ANVISA, 2004), em relação às embalagens dos RSS nenhum consultório respondeu sobre uso de sacos vermelhos com identificação de substâncias infectantes, como exigido pela normativa para resíduos que contenham sangue ou líquidos corpóreos. Os consultórios responderam que utilizam embalagens brancas com identificação de resíduos infectantes para resíduos biológicos e coletores para armazenamento de resíduos perfurocortantes, tendo sido citada a marca comercial que atende as normativas. Um consultório respondeu sobre 0 uso de garrafas para armazenamento de resíduos radiológicos, outros quatro consultórios colocaram somente a resposta como sacola plástica, não especificando o tipo e tampouco a identificação do resíduo armazenado. Em estudo realizado por Anceles et al. (2016), $91,8 \%$ dos entrevistados, nas clínicas ou consultórios odontológicos pesquisados, afirmaram separar os perfurocortantes, sendo que, destes, $89,7 \%$ afirmaram descartá-los em caixa de papelão resistente à punctura $e$ ao vazamento, com a devida simbologia.

É de suma importância a segregação correta dos resíduos gerados nos consultórios odontológicos, pois se os mesmos não forem separados corretamente de acordo com o grupo que pertencem podem causar a contaminação dos demais resíduos e, por conseguinte, do meio ambiente (ANVISA, 2006). Somente um consultório respondeu que utiliza embalagens para os líquidos gerados e também somente um consultório identificou a especialidade em radiologia, logo tem-se um indicativo de descarte incorreto de resíduos radiológicos como fixador e revelador por outros consultórios, uma vez que se obteve a resposta de 11 consultórios que utilizam revelador e fixador. Esses resíduos são utilizados para revelação de radiografias, e que se descartados de forma incorreta na rede de esgoto podem causar um alto nível de contaminação para a saúde humana e meio ambiente, devido a composição química de cada um dos resíduos. Segundo a ANVISA (2006), o revelador pode ser submetido a neutralização do $\mathrm{pH}$ utilizando vinagre e após pode ser descartado na rede de esgoto, já o fixador deve ser submetido a tratamento para recuperação da prata. No estudo realizado por Pedrosa et al. (2007), 62,3\% descartam de forma inadequada esses resíduos, o que causa prejuízos ao meio ambiente e a saúde. Em pesquisa realizada por Anceles et al. (2016) na maioria dos consultórios odontológicos, correspondendo a $82,4 \%$, os entrevistados informaram que descartam o revelador e o fixador diretamente na rede de esgoto, ou seja, de forma incorreta, desprezando o seu potencial tóxico e cumulativo de metal pesado no meio ambiente.

A forma de acondicionamento dos resíduos também foi levada em consideração conforme descrito na Figura 6 , sendo que somente 20 consultórios responderam a essa pergunta.

De acordo com a resolução n. 0358 (CONAMA, 2005), os resíduos devem ser acondicionados em recipientes que evitem vazamento, sejam resistentes, com tampa de vedação e que possam ser higienizados. Conforme a Figura 6 , os recipientes utilizados estão de acordo com a resolução para o acondicionamento dos resíduos. Segundo Garbin et al. (2015), há um desconhecimento por parte dos profissionais em relação ao acondicionamento e descarte dos resíduos odontológicos gerados nos consultórios. Há profissionais que descartam os RSS junto com os resíduos comuns, o que acaba propiciando um aumento de resíduos contaminados, se estes dois tipos de resíduos forem misturados o RSS contamina o resíduo comum, gerando assim 0 aumento de problemas no meio ambiente e também no custo com segregação e tratamento (HIDALGO et al., 2013). 


\section{Figura 6 - Recipientes utilizados para acondicionamento dos resíduos biológicos em consultórios odontológicos de Três Passos/RS}

5

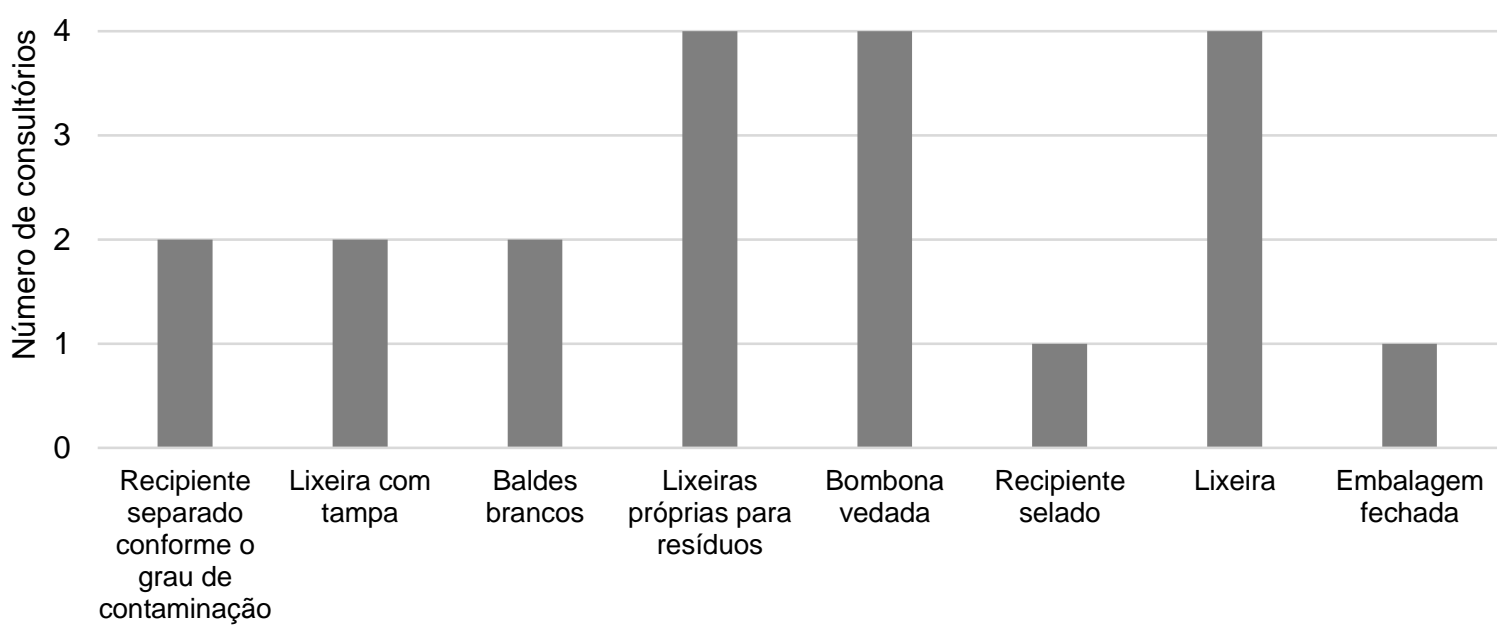

Recipientes utilizados para acondicionamento

Fonte: Autores (2018)

\subsection{Destino final dos resíduos gerados}

Para identificação do destino final dado aos resíduos, e preservação da identidade das empresas, estas foram mencionadas com base no município sede. A principal empresa que faz a coleta dos RSS possui sede no município de Santa Maria/RS, a $300 \mathrm{~km}$ de Três Passos/RS. Outra empresa, de Santa Cruz do Sul/RS distante $375 \mathrm{~km}$ do município em questão, também é responsável pela coleta dos resíduos em alguns consultórios, como apresentado na Tabela 2.

Tabela 2 - Empresas responsáveis pela coleta dos resíduos de serviços de saúde nos consultórios odontológicos de Três Passos/RS

\begin{tabular}{ccc}
\hline $\begin{array}{c}\text { Município das empresas responsáveis pela } \\
\text { coleta dos resíduos de serviços de saúde }\end{array}$ & Número de consultórios & Percentual (\%) \\
\hline Santa Maria/RS & 25 & 89 \\
Santa Cruz do Sul/RS & 2 & 7 \\
ljuí/RS & 1 & 4 \\
Total & 28 & 100 \\
\hline Fonte: Autores (2018) & &
\end{tabular}

Verificou-se também 0 conhecimento dos profissionais quanto à forma de disposição final dada pela empresa aos resíduos gerados, e somente 12 consultórios responderam a essa questão. As principais respostas registradas estão expressas na Figura 7. Compete informar que alguns consultórios registraram mais de uma resposta para a questão, assim como outros não responderam ou não souberam responder.

A frequência de coleta também foi estimada no questionário, os 28 consultórios responderam a essa questão, como apresentado na Tabela 3.

Conforme Tabela 3, destaca-se a frequência de coleta trimestral dos RSS informada por dois consultórios. Nesses casos, resíduos contendo sangue podem constituir fonte de odores indesejáveis e de contaminação. Quanto a esse aspecto a RDC no 306 (ANVISA, 2004) informa, no seu capítulo III, que "Os resíduos de fácil putrefação que venham a ser coletados por período superior a 24 horas de seu armazenamento, devem ser conservados sob 


\section{REA - Revista de estudos ambientais (Online) v.20, n. 2, p.49-61, jul./dez. 2018}

refrigeração, e quando não for possível, serem submetidos a outro método de conservação." Em estudo realizado por Silva, Shiga e Colares-Santos (2015), oito de dez clínicas odontológicas entrevistadas informaram que a coleta dos resíduos infectantes, por empresa especializada, é feita semanalmente, enquanto que as outras duas clínicas informaram que a coleta é quinzenal, porém, uma delas destacou que conforme o número de atendimentos, a coleta pode ser antecipada. Em outro estudo, realizado por Ferreira, Gorges e Silva (2009), em uma Entidade Sindical, na cidade de Brusque, no estado de Santa Catarina, os autores observaram que a coleta dos resíduos atualmente é feita uma vez por semana, e que o resíduo fica muito tempo parado no ambiente.

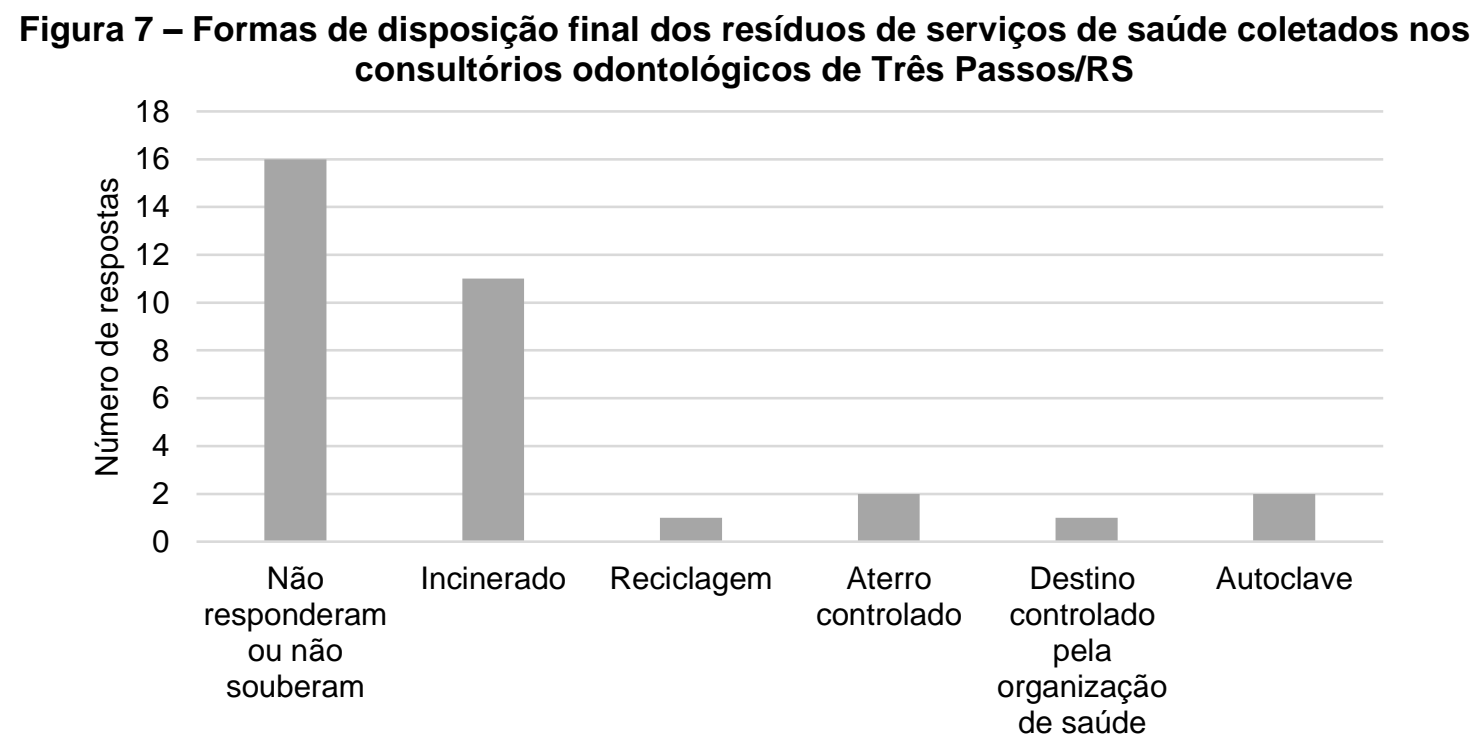

Formas de disposição final

Fonte: Autores (2018)

Tabela 3 - Frequência de coleta dos resíduos de serviços de saúde nos consultórios odontológicos de Três Passos/RS

\begin{tabular}{ccc}
\hline Frequência de coleta & Número de consultórios & Percentual (\%) \\
\hline Semanalmente & 1 & 4 \\
1 vez/mês & 7 & 25 \\
2 vezes/mês & 18 & 64 \\
Trimestralmente & 2 & 7 \\
Total & 28 & 100 \\
\hline
\end{tabular}

Fonte: Autores (2018)

Segundo a resolução no 358 (CONAMA, 2004), os geradores de RSS devem ter conhecimento sobre a licença ambiental para tratamento e disposição final dos resíduos. Neste estudo, $57,14 \%$ dos consultórios não sabiam ou não responderam qual a forma de disposição final adotada pela empresa responsável pela coleta dos resíduos em seus consultórios, o que é uma informação preocupante, tendo em vista a corresponsabilidade dos geradores com a disposição final. Conforme estudo realizado por Pedrosa et al. (2007), 67\% dos profissionais questionados desconheciam a forma de disposição final dos RSS gerados, o que evidencia a necessidade de ações de sensibilização sobre o tema para que os profissionais consultados deem maior importância ao gerenciamento dos RSS e ao destino dos resíduos gerados em seus consultórios. Diante da importância de se conhecer o destino dado aos resíduos devido aos problemas que podem acarretar, os profissionais deveriam possuir maior conhecimento e interesse em relação a esse tema. Nesse sentido, a prática odontológica abrange, portanto, atividades e interfaces que interagem não somente com o processo 


\section{REA - Revista de estudos ambientais (Online) v.20, n. 2, p.49-61, jul./dez. 2018}

saúde-doença bucal, como também com os aspectos e impactos ambientais (ANCELES et al., 2012).

No questionário também foi levado em consideração se os consultórios estudados possuíam Plano de Gerenciamento de Resíduos de Serviços de Saúde (PGRSS), tendo sido verificado que $75 \%$ dos consultórios possuem PGRSS, enquanto que 0 restante informou não possuir.

Segundo a RDC no 306 (ANVISA, 2004), todo gerador de RSS deve elaborar o PGRSS que é o documento que aponta as formas de manejo dos resíduos gerados nos estabelecimentos, devendo ser mantida uma cópia do documento disponível no consultório para consulta mediante solicitação. Conforme Nazar, Pordeus e Werneck (2005), para que o plano funcione é necessário que o local seja equipado adequadamente, e os funcionários devem receber treinamento para o manejo correto dos resíduos gerados.

\subsection{Avaliação de estratégias para disposição final dos resíduos de serviços de saúde}

Tendo em vista que $57,14 \%$ dos consultórios não responderam ou não souberam responder à questão relacionada com a disposição final dada para os resíduos pelas empresas que realizam a coleta, foram, então, realizadas pesquisas com empresas do ramo para levantar a forma de disposição final utilizada, com intuito de verificar se as alternativas utilizadas estão de acordo com as normativas do CONAMA e ANVISA.

Em um trabalho realizado em Manaus (AM) com clínicas odontológicas privadas, $45 \%$ delas relataram que eliminavam os resíduos de forma inadequada. Todas as clínicas públicas afirmaram dispor os resíduos de amálgama corretamente, e, em média, descartaram 3,83 g de Hg/dia. Este estudo destaca ainda que a condição assinalada como "clínica com disposição apropriada" não significa necessariamente que o resíduo é descartado adequadamente, uma vez que a coleta e a destinação final não foram comprovadas (SOUZA; NOZAWA; HONDA, 2012).

Uma das empresas informou que utiliza três formas de tratamento e/ou disposição final, além da coleta e transporte dos resíduos. Uma das formas é a incineração dos resíduos infectados, seguindo a recomendação da resolução no 358 (CONAMA, 2005). Outra forma é o processo de autoclavagem utilizado para esterilização dos resíduos dos Grupos A e E. Esse processo consiste em expor os materiais a vapor saturado sob pressão, sendo em seguida, após esterilização, dispostos em aterro sanitário. Por último, a empresa também possui o sistema de micro-ondas que consiste na trituração, aquecimento e aplicação de radiação eletromagnética aos materiais. Essa técnica, em condições controladas, não emite efluentes gasosos prejudiciais ao meio ambiente. A empresa também realiza o tratamento de efluentes gerados na higienização dos equipamentos e carros de coleta, bem como dos efluentes líquidos gerados no processo de autoclave. A empresa possui filiais em diversas cidades brasileiras e também em outros países.

Os valores cobrados pelas empresas que fazem a coleta não foram informados pelos consultórios estudados, mas através de pesquisas diretamente com a empresa obteve-se a informação de custo mensal de aproximadamente $R \$ 96,00$ para 150 litros de RSS. No entanto, esse custo depende da distância que a empresa precisará percorrer para coleta e transporte, bem como do grupo do resíduo e da destinação final necessária. Por esses fatores, os custos associados aos serviços podem variar e não há informações dessa natureza no site da principal empresa que realiza a coleta dos RSS nos consultórios estudados.

Por fim, destaca-se a importância da construção de novas percepções que estimulem à reflexão acerca da relação de risco associado à saúde ocupacional e ambiental, com o gerenciamento dos resíduos de serviços de saúde, bem como com a biossegurança (LEAL, 2015). Os resíduos odontológicos representam desafios consistentes para o meio ambiente, o que leva a preocupação cada vez maior com o gerenciamento desses, já que tem existido maior preocupação com a preservação da biodiversidade, tornando a odontologia uma seara fértil no enfoque da saúde ambiental (ANCELES et al., 2012). Neste sentido, tornase fundamental o estímulo à discussão deste tema associado à formação de consciência dos profissionais da saúde, bem como da sociedade como um todo, com vistas na promoção de melhor qualidade de vida para todos. 


\title{
REA - Revista de estudos ambientais (Online) v.20, n. 2, p.49-61, jul./dez. 2018
}

\section{Conclusões}

Os principais resíduos de serviços de
saúde gerados nos consultórios
odontológicos estudados são pertencentes ao
Grupo $A$, resíduos biológicos de elevado
potencial de contaminação.

Somente 10 consultórios souberam informar o número de pacientes e o volume de resíduos gerados, totalizando, em média, 0,52 litros por paciente por mês.

Todos os consultórios estudados possuem uma empresa que realiza a coleta dos RSS gerados, porém 16 consultórios não responderam ou não souberam responder a forma de disposição final.

Considerando as respostas dos consultórios, a empresa responsável pela coleta e disposição final dos RSS, mencionada pelo maior número de consultórios, segue as normas da ANVISA e CONAMA para atividade fim.

Em relação ao PGRSS, 25\% dos consultórios não possuem conhecimento sobre os Planos, embora seja obrigação disponibilizá-los para consulta de pacientes, órgãos fiscalizadores responsáveis e comunidade em geral.

\section{Health Services Waste Management in Odontological Offices of Três Passos/RS}

\begin{abstract}
The health services waste generators (HSW) must have the HSW Management Plan (HSWMP), which aims to plan the management, packaging and disposal of waste generated in health facilities. Given this relevance, the present study aimed to evaluate the health waste management in different dental offices in the city of Três Passos/RS. The methodology adopted was qualitative-quantitative, and a questionnaire was applied to 28 of the 46 private dental offices with the purpose of characterizing the types of health waste generated, quantifying the volume generated and identifying the final disposal forms. It was verified that the main waste generated in the offices are biological waste, belong to Group A. Only 10 clinics provided information on the number of patients and the volume of waste generated. It was also identified that the professionals do not have much knowledge about the final disposal forms the company responsible for the collecting gives to the HSW. Seven offices did not have HSWMP. Thus, it is necessary to focus attention on the management of health care waste in order to comply with current legislation.
\end{abstract}

Keywords: Dental offices; Health care waste; Management.

\section{Referências}

ANCELES, J. F. S. F.; SILVA, V. C.; FERNANDES, F. S.; CARVALHO, A. L. A. de. Importância da Odontologia Sustentável na Interface Saúde/Ambiente. Revista Pesquisa em Saúde, v. 13, n. 2, p. 60-66, 2012.

ANCELES, J. S. F. S.; CARVALHO, A. L. A.; MAIA FILHO, E. M; SILVA, V. C. Comportamento ambiental ligado às atividades odontológicas em São Luís, Maranhão. Revista de Pesquisa em Saúde, v. 17, n. 1, p. 27-31, 2016.

ASSOCIAÇÃO BRASILEIRA DE NORMAS TÉCNICAS - ABNT NBR no 10004. Dispõe sobre a classificação dos RSS quanto aos riscos potenciais. Rio de Janeiro, 2004.

ASSOCIAÇÃO BRASILEIRA DE NORMAS TÉCNICAS - ABNT NBR nำ 9191. Dispõe sobre os limites de peso de cada saco, proibido esvaziamento ou reaproveitamento. Rio de Janeiro, 2000.

AGÊNCIA NACIONAL DE VIGILÂNCIA SANITÁRIA (ANVISA). Resolução RDC nํ 306, de 7 de dezembro de 2004: Dispõe sobre o regulamento técnico para o gerenciamento de resíduos de serviços de saúde. Diário Oficial da União, Brasília, DF, 10 de dezembro de 2004.

AGÊNCIA NACIONAL DE VIGILÂNCIA SANITÁRIA. (ANVISA), 2006- Serviços odontológicos: prevenção e controle de Riscos, 156 p. Brasília: ANVISA, p.113-119, 2006.

CARDOSO, S. M. O.; PASSOS, K. K. M.; CARNEIRO, R. O. Sustentabilidade ambiental: nível de conscientização e atuação de estudantes de odontologia acerca da biossegurança e dos riscos provocados pelo descarte inadequado de resíduos sólidos. Revista de Ciências Médicas e Biológicas - Salvador, v. 14, n. 1, p. 57-63, 2015.

CLARO F. A.; ITO F. R.; BASTOS F. M.; RIBEIRO $M$. E. Mercúrio no amálgama odontológico: riscos da exposição, toxicidade e métodos de controlerevisão da literatura. Revista biociências, Taubaté, v. 9, n. 1, p.47-54, 2003.

CONSELHO NACIONAL DO MEIO AMBIENTE (CONAMA). Resolução no. 358, de 29 de abril de 2005. Dispõe sobre o tratamento e a disposição final dos resíduos dos serviços de saúde e dá 


\section{REA - Revista de estudos ambientais (Online) v.20, n. 2, p.49-61, jul./dez. 2018}

outras providências. Diário Oficial da União, Brasília, DF, 29 de abril de 2005.

FERREIRA, D. D. M.; GORGES, J.; SILVA, L. E. Plano de gerenciamento de resíduos do serviço de saúde: o caso do setor odontológico de uma entidade sindical. InterScience Place, ano 2, n. 9, 2009.

GARBIN, A. J. I.; WAKAYAMA, B.; BRITO, C. P.; GARBIN, C. A. S. A imperícia no gerenciamento dos Resíduos de Serviços de Saúde nos consultórios odontológicos privados. Archives of Health Investigation, v. 4, p. 1-5, 2015.

GRIGOLETTO J. C.; OLIVEIRA A. S.; MUÑOZ S. I. S.; ALBERGUINI L. B. A.; TAKAYANAGUI A. M. M. Exposição ocupacional por uso de mercúrio em odontologia: uma revisão bibliográfica. Ciência \& Saúde Coletiva, v. 13. n.2, p. 533-542, 2008.

HIDALGO, L. R. C.; GARBIN, A. J. I.; ROVIDA, T. A. S.; GARBIN, C. A. S. Gerenciamento de resíduos odontológicos no serviço público. Revista de Odontololia, v. 42, n. 4, p. 1-8, 2013.

INSTITUTO BRASILEIRO DE GEOGRAFIA E ESTATISTICA (IBGE). Cidade - Três Passos RS. Disponível em:

https://cidades.ibge.gov.br/v4/brasil/rs/trespassos/panorama. Acesso em: 24 abr. 2017.

LEAL. C. A. G. Biossegurança e gerenciamento de resíduos de serviços de saúde: a importância na formação do profissional da Odontologia na perspectiva da saúde humana e ambiental. Revista ABENO, v. 15, n. 2, p. 82-94, 2015.

NAZAR, M.W.; PORDEUS, I. A.; WERNECK, M. A. F. Gerenciamento de resíduos sólidos de odontologia em postos de saúde da rede municipal de Belo Horizonte, Brasil. Revista Panamericana de Salud Pública, v. 17, n. 4, p. 237-242, 2005.
OLIVEIRA, M. C.; MOREIRA, A. C. A. Gerenciamento dos resíduos produzidos em consultórios odontológicos de Salvador, Bahia. Revista de Ciências Médicas e Biológicas, v. 11, n. 2, p. 194-200, maio/setembro de 2012.

PEDROSA, H. L. O.; FIGUEIREDO, R. L. Q; ALBUQUERQUE, T. T. P.; COSTA, E. B.. Avaliação dos cirurgiões-dentistas sobre 0 gerenciamento dos resíduos odontológicos produzidos na pratica diária. Arquivos em Odontologia, v. 43 n. 4, p. $125-130,2007$.

SANTOS, D. T.; DIAS, K. R. H. C.; SANTOS, M. P. A. dos. Amálgama dental e seu papel na Odontologia atual. Revista Brasileira de Odontologia, v. 73, n. 1, 2016.

SILVA, C. E.; HOPPE, A. E. Diagnóstico dos Resíduos De Serviços De Saúde no interior do Rio Grande do Sul. Engenharia Sanitária Ambiental, v. 10, n. 2, p. 146-151, 2005.

SILVA, E. A.; SHIGA, R. C.; COLARES-SANTOS, L. Gestão de resíduos em clínicas odontológicas privadas em Presidente Prudente/SP. Revista Nacional de Gerenciamento de Cidades, v. 3, n. 16, p. 53-68, 2015.

SOUZA, J. P. B. L.; NOZAWA, S. R.; HONDA, R. T. Improper Waste Disposal of Silver-Mercury Amalgam. Bulletin of Environmental Contamination on Toxicology, v. 88, p. 797-801, 2012.

VASCONCELOS, M. C. Mapa com a localização de Três Passos/RS. 2017.

WORLD HEALTH ORGANIZATION (WHO). Management of waste from hospitals, Bergen, 1983. Report. Bergen (EURO Reports and Studies 97), 1983 